\title{
Renal dysfunction among adult patients in Mwanza, Tanzania: prevalence, outcomes and associated factors
}

\author{
SEMVUA B. KILONZO ${ }^{1,2^{*}}$, ABDULRASSUL T. SEIFFUDIN ${ }^{3}$, FATMA A. BAKSHI ${ }^{1}$ and DANIEL W. GUNDA ${ }^{1,2}$ \\ ${ }^{1}$ Catholic University of Health and Allied Sciences, P.O. Box 1464, Mwanza, Tanzania \\ ${ }^{2}$ Bugando Medical Centre, P.O. Box 1370, Mwanza, Tanzania \\ ${ }^{3}$ Morogoro Regional Referral Hospital, P. O Box 110, Morogoro, Tanzania.
}

\begin{abstract}
Background: The prevalence and mortalities due to renal diseases is estimated to be high in sub-Saharan Africa. However, little is known about these conditions among the hospitalized adult-patients in Tanzania. The objective of this study was to determine the magnitude, associated factors and outcomes of renal dysfunction among the inpatients at Bugando Medical Centre in Mwanza, Tanzania.

Methods: An analytical cross-sectional study was used to determine the prevalence and predictors while prospective cohort design was employed to determine the outcomes. Demographic, clinical and laboratory data were collected from all adult inpatients. For those patients with initial estimated Glomerular Filtration Rate (eGFR) of $<60 \mathrm{ml} / \mathrm{min} / 1.73 \mathrm{~m}^{2}$, a repeat creatinine test was done after 3 -months to diagnose the chronic kidney disease.

Results: Out of 637 patients, 48.2\% were females and the median age was 45 years. Twenty-eight percent of the study population had renal dysfunction. The prevalence of Chronic Kidney Disease was 69.5\% (41/59). The odds of having renal dysfunction was strongly predicted by older age $(p=0.009)$, female sex $(p=0.004)$, heart failure $(p<0.001)$, diabetes $(p=0.04)$, decreased urine output $(p<0.001)$ and proteinuria $(p=0.004)$. Mortality, both in-hospital (3.23 [2.19-4.74], $\mathrm{p}<0.001)$ and at 1-month post-discharge (3.07[2.13-4.41], $\mathrm{p}<0.001)$ was found to be significantly higher in patients with renal dysfunction.

Conclusion: This study has demonstrated a high prevalence of renal dysfunction and associated mortalities. This strongly emphasizes the need to increase awareness among clinicians in Tanzania on renal diseases so as to pro-actively screen, prevent, diagnose and provide early treatment of renal dysfunction among hospitalized patients.
\end{abstract}

Keywords: renal dysfunction, kidney, injury, disease, prevalence, outcomes, Tanzania

\section{Introduction}

Acute kidney injury (AKI) and chronic kidney diseases (CKD) are common in Africa and they cause high mortalities. AKI reportedly affects about 13 million people annually, of whom $85 \%$ are from low income countries. About 1.7 million deaths are thought to be caused by AKI annually (Mehta et al., 2015). According to recent meta-analyses, the prevalence of CKD in Africa is estimated to be 13.9\% (Li et al., 2013; Stanifer et al., 2014). The increase in incidence of these diseases is reflected by increase in prevalence of precipitators like diabetes mellitus, cardiovascular diseases and human immunodeficiency virus (HIV) infection (Arogundade \& Barsoum, 2008; Okunol et al., 2012). High mortality in the resource-limited countries in sub-Saharan Africa (SSA) is mostly attributed to lack of awareness of kidney diseases, unavailability of prevention programmes and poor access to renal replacement therapy (RRT) which is either due to high costs or unavailability of such interventions (Callegari et al., 2012; Pozo et al., 2012).

Reports from the USA and Europe have demonstrated that AKI and CKD are important co- morbidities among hospitalized adults (Susantitaphong et al., 2013), and majority of patients with CKD are unaware of their renal disease status (Saunders et al., 2015). Little is known about renal dysfunction (RD) among hospitalized adult-patients in most SSA countries including

\footnotetext{
* Correspondence Email: sekipcb@yahoo.com
} 
Tanzania. A need to establish the status of these diseases is therefore desirable. This study was therefore carried out to determine the prevalence, associated factors and outcomes of renal dysfunction among the inpatients at Bugando Medical Centre (BMC) in north-western Tanzania.

\section{Materials and Methods}

\section{Study site and design}

The study was conducted in the adult medical wards of BMC, a consultant and teaching hospital in Mwanza, Tanzania from October 2013 to March 2014. BMC is the zonal referral hospital for the Lake Victoria zone which serves about one-third of the country's population. The hospital has approximately 1,000 beds with an average of 10 medical admissions daily. An analytical crosssectional study design was used to determine the prevalence and predictors while a prospective cohort study was used to determine the outcomes.

\section{Data collection}

All patients over 18 years of age who were admitted to the medical wards of BMC during the study period were eligible for the study and those who consented were enrolled in the study. Demographic and clinical data were collected within 24 hours from the time of admission. A modified structured version of the World Health Organization (WHO) Stepwise approach to surveillance (STEPS) questionnaire was used (WHO, 2011). Additional questions regarding the clinical features of renal dysfunction were added to the questionnaire.

A standardized physical examination was performed for each subject. This included measurements of blood pressure (BP), height, and weight. BP was measured with a mercury sphygmomanometer using standard technique (James et al., 2014). BP was considered to be elevated if it was equal to or greater than $140 / 90 \mathrm{mmHg}$. The body mass index (BMI) was calculated for all subjects and classified using the WHO classification of obesity (Nishida et al., 2010). Venipuncture was performed on all subjects to obtain blood samples for serum creatinine, HIV and random blood glucose (RBG). Analysis of creatinine was done using an automated machine (Cobas Integra 400 Plus analyzer; Roche, Germany) and the obtained value was used to calculate estimated Glomerular Filtration Rate (eGFR) by using CKD-EPI equation (Levey et al., 2009). Serum creatinine was repeated during a follow-up visit at a 3-month interval for patients with initial eGFR of $<60 \mathrm{ml} / \mathrm{min} / 1.73 \mathrm{~m}^{2}$. RBG was done using a glucometer (GlucoPlus; Glocoplus Inc. Canada), and HIV tests were performed according to the Tanzanian National Guidelines for Provider-Initiated Testing and Counseling (PITC) (MoHSW, 2007). Urine samples were collected by the patient themselves in sterile containers. Within five minutes of urine collection, urinalysis was performed by using urine dipstick (Multistix; Siemen Medical Solutions Diagnostics, USA).

Renal dysfunction in this study was defined as low eGFR $\left(<60 \mathrm{ml} / \mathrm{min} / 1.73 \mathrm{~m}^{3}\right)$ on admission while CKD was defined according to the Kidney Disease Improving Global Outcomes (KDIGO) diagnosis criteria that is persistently low eGFR $\left(<60 \mathrm{ml} / \mathrm{min} / 1.73 \mathrm{~m}^{3}\right)$ on a follow-up visit at 3 months (Zarbock et al., 2014). Primary outcome was the prevalence of renal dysfunction while secondary outcomes were the factors associated with renal dysfunction and mortality rates of such patients which occurred both in the hospital and at their homes 1 and 3 months' postdischarge.

\section{Data analysis}

Data were analyzed using STATA programme version 13 (College Station, Texas, USA). Descriptive statistics were computed by determining means and standard deviations for normally distributed continuous variables. Medians and inter-quartile ranges were used for abnormally distributed continuous variables as well as for proportions for categorical variables. Means, medians and proportions were compared using the student's t-test, Wilcoxon rank sum test and Pearson chi- 
square test or Fisher's exact test, respectively. P-value of less than 0.05 was considered significant. Predictors were evaluated by univariate analysis. Predictors with a p-value of $<0.10$ by univariate analysis were included in the multivariate logistic regression analysis. The odds ratios with $95 \%$ confidence intervals were determined.

\section{Ethical considerations}

Ethical approval was sought and obtained from the Catholic University of Health and Allied Science/Bugando Medical Centre joint Committee of Research and Publications (Ref. No. CREC 1054/2013). Participants were recruited only after giving an informed written consent or after receiving consent given by a close relative in case of participants who were mentally unstable. All results were provided to the clinicians involved in patient's care and the patients were managed as per BMC's protocol.

\section{Results}

\section{Baseline characteristics}

A total of 637 patients were included in the analysis. Out of these, $307(48.2 \%)$ were females and the median age was 45 years (IQR 32-61 years). A history of hypertension was present in 160 (25.1\%) patients. Twenty-six (4.1\%) of the 637 patients had history of kidney disease. Both, the systolic and diastolic mean blood pressures were normal [118 (102-140) and 76 (70-70) mmHg, respectively] (Table 1 ).

Table 1: Baseline characteristics of the study subjects

\begin{tabular}{|c|c|c|}
\hline Characteristic & & Number (\%) or Median [IQR] \\
\hline \multirow[t]{4}{*}{ BMI } & & $22.6[20.3-25 \cdot 3]$ \\
\hline & Underweight $\mathrm{BMI}<18.5$ & $83(12.9)$ \\
\hline & Normal BMI $>=18.5 \&<25$ & $390(60.6)$ \\
\hline & Overweight $\mathrm{BMI}>=25 \&<30$ & $102(15.8)$ \\
\hline \multirow[t]{2}{*}{ Smoking } & Smoker & $134(21.0)$ \\
\hline & Never & $503(78.7)$ \\
\hline \multirow[t]{3}{*}{ Alcohol } & Never & $404(62.4)$ \\
\hline & Prior to last month & $190(29.4)$ \\
\hline & In last month or current & $53(8.2)$ \\
\hline Prior use of herbal medicines & & $130(20.5)$ \\
\hline History of hypertension & & $160(25.1)$ \\
\hline \multirow[t]{3}{*}{$\mathrm{SBP}^{*}$ in $\mathrm{mmHg}$} & Hypotension $(<90)$ & $25(3.9)$ \\
\hline & Normal BP $(90-139)$ & $439(68.2)$ \\
\hline & Hypertension (>140) & $178(28.0)$ \\
\hline \multirow[t]{3}{*}{$\mathrm{DBP}^{\dagger}$ in $\mathrm{mmHg}$} & Hypotension $(<60)$ & $42(6.5)$ \\
\hline & Normal BP (6o-89) & $421(65.4)$ \\
\hline & Hypertension (>90) & $181(28.1)$ \\
\hline CCF by Framingham criteria & & $145(22.4)$ \\
\hline History of kidney disease & & $26(4.1)$ \\
\hline Renal dysfunction & eGFR $<60 \mathrm{~mL} / \mathrm{min} / 1.73 \mathrm{~m} 2$ & $175(27.5)$ \\
\hline \multirow[t]{2}{*}{ Urine output } & Normal & $560(87.9)$ \\
\hline & Decreased & $77(12.1)$ \\
\hline History of diabetes & & $46(7.2)$ \\
\hline \multirow[t]{3}{*}{ HIV rapid test } & Known HIV+ & $117(18.4)$ \\
\hline & Newly tested HIV+ & $32(5.0)$ \\
\hline & Newly tested HIV - & $473(74.3)$ \\
\hline
\end{tabular}

Key: * Systolic blood pressure; ${ }^{\dagger}$ Diastolic blood pressure 
Of the study participants, majority $(47,7 \%)$ had primary school education. Other were had either completed post-secondary education (11.1\%) or had incomplete primary school education (36.7\%). Peasants accounted for majority of the study subjects (47.1\%), followed by self-employed (28.8\%) and civil servant or business men/women (24.2\%).

\section{Prevalence and factors associated with renal dysfunction}

Among 637 patients admitted, 175 (27.5\%) were found to have renal dysfunction. Of these, 56.6\% patients died and $9.7 \%$ lost follow-up leaving only 59 for analysis at 3-month interval. The prevalence of chronic kidney disease was 69.5\% (41/59). Using univariate analysis, old age $(\geq 45$ years) (OR 1.17 [0.97-1.41] $p<0.001$ ), female sex (OR 1.45[1.02-2.05], $p=0.04$ ) and overweight (OR $1.63[1.03-2.57] p=0.04)$ were found to predict renal dysfunction. Other clinical predictors of renal dysfunction were hypertension; both by history (OR 3.06 [2.09-4.49] $\mathrm{p}<0.001)$ and measurement on admission (2.13 [1.47-3.09] $\mathrm{p}<0.001)$, congestive heart disease as determined by Framingham criteria (OR 2.92 CI [1.99-4.29] $\mathrm{p}<0.001$ ), diabetes mellitus (OR 3.51 [1.91-6.45] $\mathrm{p}=0.001$ ) and history of decreased urine output (OR 3.01 [1.85-4.89] $\mathrm{p}<0.001)$ (Table 2).

Table 2: Factors associated with renal dysfunction among 637 patients admitted in Medical wards at BMC by univariate analysis

\begin{tabular}{|c|c|c|c|c|c|}
\hline Characteristics & & $\begin{array}{l}\text { No. (\%) with RD } \\
(\mathrm{n}=175)\end{array}$ & $\begin{array}{l}\text { No. (\%) without RD } \\
(n=462)\end{array}$ & $\begin{array}{l}\text { Odds ratio } \\
{[95 \% \mathrm{Cl}]}\end{array}$ & P-value \\
\hline $\mathrm{H} / \mathrm{O}^{*} \mathrm{KD}^{\dagger}$ & & $14(8.0)$ & $12(2.6)$ & $3.25[1.47-7.17]$ & 0.004 \\
\hline $\mathrm{H} / \mathrm{O} \mathrm{HTN}^{\ddagger}$ & & $73(42.2)$ & $87(19.3)$ & 3.06 [2.09-4.49] & $<0.001$ \\
\hline $\mathrm{H} / \mathrm{O} C \mathrm{CF}$ & & $40(23.1)$ & $40(8.8)$ & $3.11[1.92-5.02]$ & $<0.001$ \\
\hline $\mathrm{H} / \mathrm{O}$ diabetes & & $25(14.4)$ & $21(4.6)$ & $3.51[1.91-6.45]$ & $<0.001$ \\
\hline Urine output & $\begin{array}{l}\text { Normal } \\
\text { Decreased }\end{array}$ & $\begin{array}{l}137(78.3) \\
38(21.7)\end{array}$ & $\begin{array}{l}423(91.6) \\
39(8.4)\end{array}$ & $3.01[1.85-4.89]$ & $<0.001$ \\
\hline $\mathrm{SBP}$ in $\mathrm{mmHg}$ & $\begin{array}{l}\text { Hypotension }(<90) \\
\text { Hypertension }(>139)\end{array}$ & $\begin{array}{l}10(5.7) \\
71(40.6)\end{array}$ & $\begin{array}{l}14(3.0) \\
112(24.2)\end{array}$ & $\begin{array}{l}1.94[0.84-4.45] \\
2.13[1.47-3.09]\end{array}$ & $\begin{array}{l}0.12 \\
<0.001\end{array}$ \\
\hline $\mathrm{DBP}$ in $\mathrm{mmHg}$ & $\begin{array}{l}\text { Hypotension }(<60) \\
\text { Hypertension }(>89)\end{array}$ & $\begin{array}{l}14(8.0) \\
101(57.8)\end{array}$ & $\begin{array}{l}27(5.8) \\
346(74.9)\end{array}$ & $\begin{array}{l}1.40[0.72-2.74] \\
0.54[0.37-0.78]\end{array}$ & $\begin{array}{l}0.32 \\
0.001\end{array}$ \\
\hline $\begin{array}{l}\text { CCF by Framingham } \\
\text { criteria }\end{array}$ & & $65(37.1)$ & 78 (16.9) & $2.92[1.99-4.29]$ & $<0.001$ \\
\hline & $\begin{array}{ll}\text { Albumin } & 0 \\
+1 & \\
+2 & \\
+3 & \\
\text { RBC } & 0 \\
+1 & \\
+2 & \\
+3 & \end{array}$ & $\begin{array}{l}98(56.0) \\
32(18.3) \\
28(16.0) \\
17(9.7) \\
137(78.3) \\
17(9.7) \\
10(5.7) \\
11(6.3)\end{array}$ & $\begin{array}{l}345(74.7) \\
43(9.3) \\
43(9.3) \\
4(0.9) \\
376(81.4) \\
13(2.8) \\
11(2.4) \\
14(3.0)\end{array}$ & $\begin{array}{l}1 \\
2.8[1.71-4.62] \\
2.4[1.44-4.04] \\
15.0[4.18-53.50] \\
1 \\
3.53[1.67-7.45] \\
2.46[1.02-5.90] \\
2.12[0.94-4.77]\end{array}$ & $\begin{array}{l}1 \\
<0.001 \\
0.001 \\
<0.001 \\
1 \\
0.001 \\
0.045 \\
0.07\end{array}$ \\
\hline
\end{tabular}

Key: ${ }^{*}$ History of; ${ }^{\dagger}$ Kidney disease; ${ }^{\ddagger}$ Hypertension

When these factors were subjected to multivariate analysis, old age $(p=0.009)$, female sex $(p=0.004)$, heart failure by history $(p=0.008)$ and Framingham criteria $(p<0.001)$, history of diabetes $(p=0.04)$ history of decreased urine output $(p<0.001)$ and proteinuria of $3^{+}(p=0.004)$ remained as strong predictors of renal dysfunction (Table 3 ). 
Table 3: Factors associated with renal dysfunction among patients admitted at BMC by multivariate analysis ( $\mathrm{N}=637)$

\begin{tabular}{lll}
\hline Characteristic & Odds ratio [Confidence Interval] & P value \\
\hline Female sex & $1.49[1.03-2.19]$ & 0.04 \\
Age $(\geq 45$ versus $<45$ ) years & $1.02[1.00-1.03]$ & 0.009 \\
History of heart failure & $2.09[1.24-3.61]$ & 0.008 \\
History of diabetes & $2.09[1.05-4.15]$ & 0.04 \\
Reduced urine output & $1.83[1.11-3.02]$ & $<0.001$ \\
Systolic hypertension (SBP $>139)$ & $2.12[1.10-4.08]$ & 0.024 \\
Heart failure by Framingham criteria & $3.08[2.02-4.69]$ & $<0.001$ \\
Albuminuria $(+3)$ & $15.0[4.18-53.50]$ & $<0.001$ \\
\hline
\end{tabular}

\section{Patient's outcomes}

One hundred and seventy-five (27.5\%) out of 637 patients were found to have renal dysfunction. During the post admission follow-up, the re-admission rates were higher both at 1 and 3 months of patients with renal dysfunction than those without renal dysfunction. When mortalities between two groups were compared, they were significantly higher in patients with renal dysfunction than those without renal dysfunction both in the hospital and at one month follow up ( $p$ <0.001). Mean duration of stay in hospital was the same ( 6 days) in both subjects. These differences also remained statistically significant even after adjusting for age, sex and HIV status (Table 4).

Table 4: In-hospital, 1- and 3-month outcome post-discharge among adults admitted with renal dysfunction and those with other conditions

\begin{tabular}{|c|c|c|c|c|}
\hline Outcome Number/Median & $\begin{array}{l}\text { Renal dysfunction } \\
(\mathrm{N}=175)\end{array}$ & $\begin{array}{l}\text { Other conditions } \\
(\mathrm{N}=462)\end{array}$ & $\begin{array}{l}\text { Odds } \\
{[95 \% \mathrm{Cl}]}\end{array}$ & P-value \\
\hline eGFR (ml/min/1.73m²) & $41[25-49]$ & $90[90-90]$ & NA & NA \\
\hline eGFR $\left(<15 \mathrm{ml} / \mathrm{min} / 1.73 \mathrm{~m}^{2}\right)$ & $21(11.0 \%)$ & NA & NA & NA \\
\hline In-hospital mortality rate & $62(35.4 \%)$ & $80(17.3 \%)$ & $3.23[2.19-4.74]$ & $<0.001$ \\
\hline Duration of hospital stay (days) & $6[3-8]$ & $6[4-10]$ & $0.97[0.93-1.00]$ & 0.07 \\
\hline Mortality at 1 month & $26 / 98(26.5 \%)$ & $62 / 346(17.9 \%)$ & $3.07[2.13-4.41]$ & $<0.001$ \\
\hline Readmission rate at 1 month & $33 / 98(33.7 \%)$ & $68 / 345(19.7 \%)$ & $1.96[1.20-3.18]$ & 0.007 \\
\hline Mortality at 3 month & $11 / 72(15 \cdot 3 \%)$ & $29 / 284(10.2 \%)$ & $0.63[0.29-1.33]$ & 0.23 \\
\hline Readmission rate at 3 month & $15 / 70(21.4 \%)$ & $43 / 282(15 \cdot 3 \%)$ & $1.52[0.78-2.92]$ & 0.21 \\
\hline Chronic kidney disease & $41 / 59(69.5 \%)$ & NA & NA & NA \\
\hline
\end{tabular}

Key: $\mathrm{NA}=$ not applicable; $\mathrm{Cl}=$ Confidence Interval

\section{Discussion}

This study has demonstrated that nearly one-third of the patients had renal dysfunction. Of these, two thirds had CKD. This prevalence is unacceptably high as compared to overall prevalence of CKD in other SSA countries (Sumaili et al., 2009; Stanifer et al., 2014). Higher prevalence in our study can be explained by an in-hospital based environment which involved inpatients study participants. In addition, poor community awareness on renal diseases, inadequate health facilities and absence of proper renal prevention programmes are likely to have contributed to this higher prevalence. Similar findings have also been reported from other surveys (Carter \& Callegari, 2007; Arogundade \& Barsoum, 2008).

Similar to our findings, advanced age and low level of education have been demonstrated to be associated with renal dysfunction elsewhere (Bello et al., Singh et al., 2009; Sumaili et al., 2010; Fraser et al., 2013; Khajehdehi et al., 2014). However, most of our patients were relatively 
younger than those in the developed countries where patients are predominantly middle-aged and elderly (Castro \& Coresh, 2009). This is possibly a reflection of the higher prevalence of the predisposing illnesses like hypertension and infections causing glomeruloneprhitis and interstitial nephritis in this age group in most developing countries (Naicker et al., 2003; Fabian \& Naicker, 2009; Hall et al., 2011; Peck et al., 2013).

In agreement with many other studies, hypertension, diabetes mellitus and congestive heart failure were found to be associated with renal dysfunction in our study. Renal dysfunction is usually a complication of these conditions if not timely treated. A concurrent increase in prevalence of these diseases in our population with inadequate control (Peck et al., 2013; Kamuhabwa \& Charles, 2014) explains their positive relation to renal dysfunction. In another study at the same center, Janmohamed et al. (2013) reported very high prevalence of CKD among diabetic patients attending outpatient clinic.

HIV/AIDS in our study was not found to be significantly associated with renal dysfunction. However, a recent study in Ghana has indicated positive association between the two conditions (Sarfo et al., 2013). This association has also been implicated by low CD4 count (Msango et al. 2011). A study by Mpondo et al. (2014) has suggested the improvement of renal function in these patients following ART drugs. Majority of our HIV-infected patients were aware of their status and were already enrolled for care and treatment services including the use of ART drugs that might have induced an improvement of their renal functions. The high mortality among patients with renal dysfunction found in our study during hospitalization and post-discharge is consistent with other findings elsewhere (Ympa et al., 2005). A high relative risk for all-cause death associated with CKD observed in this study has also been reported elsewhere by Tonelli et al. (2006).

This study had some limitations which include the inability to perform renal biopsy for establishing a progression of renal disease and loss of follow-up to some patients at 3-month post-discharge. Despite these shortcomings, the findings are important and relevant as they provide a broad picture on the situation locally and a baseline information for further studies on the subject.

The current study has conclusively demonstrated that prevalence and mortality rates are high among BMC in-patients with renal dysfunction and that majority of them are unaware of their status. It is justifiable belief that our findings emphasize the need for increasing awareness on the renal diseases among clinicians in Tanzania so as to screen, prevent, diagnose and treat renal dysfunction early. On the bases of these findings, we strongly urge and recommend provision of renal replacement therapy services at BMC in order to reduce high burden of morbidity and mortality from these conditions. We also recommend a follow-up study of these patients to determine long term outcome on their health conditions.

\section{Conflict of Interests}

The authors declare that they have no conflict of interests.

\section{Authors' Contribution}

SBK, ATS, collected the clinical information and managed the patient; SBK, FAB, DWG wrote the manuscript. All authors critically revised the manuscript and approved the final draft.

\section{Acknowledgements}

We thank the staff members of the Department of Internal Medicine of Bugando Medical Centre for their support. 


\section{References}

Arogundade, F.A. \& Rashad, S.B. (2008) CKD Prevention in Sub-Saharan Africa: A Call for Governmental, Nongovernmental, and Community Support. American Journal of Kidney Diseases 51, 515-523.

Bello, A.K., Peters, J., Rigby, J., Rahman, A.A. \& Meguid, E. (2008) Socioeconomic status and chronic kidney disease at presentation to a renal service in the United Kingdom. Clinical Journal of the American Society of Nephrology 3: 1316-1323.

Callegari, J.G., Carter, M., Finkelstein, F.O., Handelman, G.J., Kilonzo, K.G., Kotanko, P., Levin, N.W. \& Yeates, K.E. (2012) Peritoneal dialysis for acute kidney injury in Sub-Saharan Africa: challenges faced and lessons learned at Kilimanjaro Christian Medical Centre. Kidney International 81, 331-333.

Carter, M. \& Callegari, J.G. ( 2007) Proposed treatment program for acute renal failure (ARF) in the United Republic of Tanzania as a model for Sub-Saharan Africa. Journal of Hospital Marketing \& Public Relations 18, 81-88.

Castro, A.F. \& Coresh, J. (2009) CKD Surveillance Using Laboratory Data from the PopulationBased National Health and Nutrition Examination Survey (NHANES). American Journal of Kidney Diseases 53, S46-55.

Fabian, J. \& Naicker, S. (2009) HIV and Kidney Disease in Sub-Saharan Africa. Nature Reviews Nephrology 5: 591-598.

Fraser, S., Casey, M., Ho, M.Y., Nutbeam, D., Roderick, P.J., Simon, D.S. \& Taal, M.W. (2013) Prevalence and associations of limited health literacy in chronic kidney disease: a systematic review. Nephrology, Dialysis, Transplantation 28, 129-137.

James, P.A., Carter, B.L., Cushman, W.C., Dennison-Himmelfarb, C., Handler, J., Lackland, D.T. \& Oparil, S. (2014) Evidence-based guideline for the management of high blood pressure in adults: report from the panel members appointed to the eighth joint national committee. Journal of the American Medical Association 311, 507-520.

Kamuhabwa, J., Appolinary, R. \& Charles, E. (2014) Predictors of poor glycemic control in type 2 diabetic patients attending public hospitals in Dar es Salaam. Drug, Healthcare and Patient Safety $155-165$.

Khajehdehi, A., Malekmakan, L., Pakfetrat, M., Parviz, J., Roozbeh, J. \& Sayadi, M. (2014) Prevalence of chronic kidney disease and its contributing risk factors in Southern Iran: A cross-sectional adult population-based study. Iranian Journal of Kidney Diseases 8: 109-115.

Levey, M., Andrew S, Feldman, H.I., Castro, A.F., Kusek, J.W., Lesley, A.S., Schmid, C.H. \& Zhang, Y.L. (2009) A new equation to estimate glomerular filtration rate. Annals of Internal Medicine 150, 604-612.

Li, P.K., Burdmann, E.A. \& Mehta, R.L. (2013) Acute Kidney Injury: Global Health Alert. Transplantation 95, 653-57.

Mehta, R.L., Burdmann, E.A., Cerdá, J., García-García, G., Marcello, T.J. \& Susantitaphong, P. (2015). International Society of Nephrology's oby25 Initiative for Acute Kidney Injury (Zero Preventable Deaths by 2025): A Human Rights Case for Nephrology. Lancet 385 (9987), 2616-2643.

MoHS (2007) Guidelines for HIV Testing and Counselling in Clinical Setting. Ministry of Health and Social Welfare, Dar es Salaam, Tanzania. http://www.who.int/hiv/topics/vct/TZ_PITCGuidelines final edit_July2007.pdf.

Mpondo, B.C., Downs, J.A., Fitzgerald, D.W., Kabangila, R., Kalluvya, S.E., Kidenya, B.R., Lucheri, E. \& Peck, R.N. (2014) Impact of antiretroviral therapy on renal function among HIV-infected Tanzanian adults: a retrospective cohort study. PloS One 9 (2): e89573.

Msango, L., Downs, J.A., Fitzgerald, D.W., Kabangila, R., Kalluvya, S.E., Kidenya, B.R. \& Peck, R.N. (2011) Renal dysfunction among HIV-infected patients starting antiretroviral therapy. AIDS 25 
(11): 1421-1425.

Naicker, S. (2003) End-stage renal disease in Sub-Saharan and South Africa. Kidney International. Supplement 83, S119-122.

Nishida, C., Ko, G.T. \& Kumanyika, S. (2010) Body Fat Distribution and Noncommunicable Diseases in Populations: Overview of the 2008 WHO Expert Consultation on Waist Circumference and Waist-Hip Ratio. European Journal of Clinical Nutrition 64, 2-5.

Okunola, O. A., Akinsola, \& Ayodele, O. (2012) Kidney Diseases in Africa: Aetiological Considerations, Peculiarities and Burden. African Journal of Medicine and Medical Sciences 41, 119-133.

Paweena, S., Abulfaraj, M., Alqahtani, F., Cerda,J., Cruz, D.N., Ioannis, K. \& Jaber, B.L. (2013) World Incidence of AKI: A Meta-Analysis. Clinical Journal of the American Society of Nephrology 8, 1482-1493.

Peck, R.N., Downs, J.A., Fitzgerald, D.W., Majinge, C.R., Mtabaji, J.P. \& Smart, L.R., (2013) Hypertension-related diseases as a common cause of hospital mortality in Tanzania: A 3-year prospective study. Journal of Hypertension 31, 1806-1811.

Pozo, M.E., Groen, Hardy, M.A. \& Kamara, T.B. (2012) An Overview of Renal Replacement Therapy and Health Care Personnel Deficiencies in Sub-Saharan Africa. Transplant International 25, 652-657.

Sarfo, F.S., Appiah, L., Bedu-Addo, G., Chadwick, D.R,. Hardy, Y., Keegan, R., Longstaff, L., Norman, B., Phillips, R. \& Shakoor, S. (2013) High prevalence of renal dysfunction and association with risk of death amongst HIV-Infected Ghanaians. Journal of Infection 67, 4350.

Saunders, M.R., Kim, S.D., Patel, N., Meltzer, D.O. \& Chin, M.H. (2015) Hospitalized patients frequently unaware of their chronic kidney disease. Journal of Hospital Medicine 10, 619-622.

Singh, S., Beniwal, P., Ingle, G.K., Jami, A., Lal, M., Meena, G.S., Narinder P. \& Saini, V.K. (2009) Prevalence of Low Glomerular Filtration Rate, Proteinuria and Associated Risk Factors in North India Using Cockcroft-Gault and Modification of Diet in Renal Disease Equation: An Observational, Cross-Sectional Study. BMC Nephrology 10: 4.

Stanifer, J.W., Jing, B., Helmke, N., Mukerjee, R., Naiker, S. \& Patel, U. (2014). The epidemiology of chronic kidney disease in sub-Saharan Africa: A systematic review and meta-analysis, The Lancet Global Health 2 (3): e174-81.

Sumaili, J., Cohen, E.P., Ernest, K., Krzesinski, K.M. \& Nseka, N.M. (2010) Epidemiology of chronic kidney disease in the Democratic Republic of Congo: review of cross-sectional studies from Kinshasa, the Capital. Néphrologie \& Thérapeutique 6 (4): 232-239.

Tariq, A., Izhar K., Gordon P., Macleod A., Smith, W., Townend J. \& William S. (2007) Incidence and outcomes in acute kidney injury: a comprehensive population-based study. Journal of the American Society of Nephrology 18, 1292-1298.

Tonelli, M., Culleton, B., Finlay, M.A., Fok, M., Garg, A.X., House, A.C. \& Wiebbe, N. (2006) Chronic Kidney Disease and Mortality Risk: A Systematic Review. Journal of the American Society of Nephrology 17, 2034-2047.

Victoria, H., Henriksen,O., Lohse, N. \& Thomsen, R.W. (2011) Diabetes in Sub Saharan Africa 19992011: Epidemiology and public health implications. a systematic review. BMC Public Health 11: 564.

Xue, L., Lou, Y.X., Ran, Z., Wang, C. \& Zhang, X. (2014) Prevalence of Chronic Kidney Disease and Associated Factors among the Chinese Population in Taian, China. BMC Nephrology 15: 205.

Ympa, Y.P., Sakr, Y., Reinhart, K. \& Vincent, J.L. (2005) Has Mortality from Acute Renal Failure Decreased? A Systematic Review of the Literature. American Journal of Medicine 118, 827832.

Zarbock, A., John, S., A. \& Kindgen-Milles, D. (2014) New KDIGO Guidelines on Acute Kidney Injury. Practical Recommendations. Der Anaesthesist 63, 578-588. 